\title{
Limites das abordagens microeconômicas da redução da jornada de trabalho
}

Paulo Sérgio Fracalanza ${ }^{1}$

Resumo: O objetivo deste artigo consiste em apresentar as insuficiências de um conjunto de análises microeconômicas que, recorrendo ao instrumental das teorias de emprego novo-keynesianas, procuram avaliar os impactos potenciais sobre o emprego da adoção de uma política de redução da jornada de trabalho. Inicialmente, descrevem-se as principais características da lei das "35 horas" na França, o movimento da duração do trabalho ao longo de um largo período de tempo nos países capitalistas e o mecanismo que franqueia o caminho para uma redução da jornada de trabalho. A seguir, evidencia-se que, apesar do interesse crescente pelos resultados dos modelos microeconômicos de inspiração novo-keynesiana na investigação dos impactos potenciais de uma política de redução da jornada de trabalho, as insuficiências das abordagens da ortodoxia obscurecem em muito os possíveis resultados benéficos desta política.

Palavras-chave: Redução da jornada de trabalho; Modelos NovosKeynesianos; Lei das "35 horas".

\section{The limits of microeconomic approaches to working time reduction}

\begin{abstract}
This article aims to present some insufficiencies of the New-Keynesian microeconomic models used to estimate the potential impacts on employment of a working time reduction policy. Firstly, it is presented the main characteristics of the "35 hours week" Law in France, a long historical perspective of the working time reduction process in some capitalistic countries and an understanding of the mechanism that clears the way to a reduction of working time. Secondly, it is asserted the main results and the growing interest in the New-Keynesian microeconomic models used to estimate the potential effects on employment of a
\end{abstract}

1 Professor Doutor no Instituto de Economia da Unicamp, Professor Doutor e Coordenador do curso de Ciências Econômicas nas Faculdades de Campinas (FACAMP), Pesquisador do Núcleo de Economia Industrial e da Tecnologia (NEIT) do IE/Unicamp. E-mail: fracalan@eco.unicamp.br ou fracalan@gmail.com. 
FRACALANZA, P. Limites das abordagens microeconômicas da redução...

working time reduction policy. Finally, the last section is dedicated to provide some insights on the insufficiencies of these microeconomic models and to argue that these flaws could obscure the potential benefits of that policy.

Key-words: Working time reduction policy; New-Keynesian models; "35 hours week» Law.

JEL: E24, J64, J68

\section{Introdução}

Atualmente, na Europa e sobretudo na França, as atenções ainda se voltam para os resultados da lei das " 35 horas", que, com o objetivo explícito da criação de empregos, reduziu a jornada de trabalho dos franceses.

Essa idéia representou uma mudança de perspectiva com relação ao debate dos anos sessenta. De fato, naquele momento, os países desenvolvidos viviam na confortável situação de quase pleno emprego. As reivindicações pela redução da jornada de trabalho objetivavam, acima de tudo, a melhoria das condições de trabalho e de vida, libertando o trabalhador das limitações impostas por jornadas muito longas.

Com efeito, finda a Segunda Guerra Mundial, a Europa viveu durante quase vinte anos com taxas de desemprego negligenciáveis. Entretanto, em fins dos anos 60 e sobretudo depois do primeiro choque do petróleo em 1973, os europeus assistiram novamente à escalada do desemprego. No breve intervalo de 1970 e 1980 , a taxa de desemprego mais que dobrou para o conjunto dos países da União Européia e, nos anos seguintes, voltaria a dobrar (Summers \& Blanchard 1990: 227). A persistência do desemprego e sua aparente imunidade contra todas as medidas implementadas desde então para debelá-lo autorizou os policy makers europeus a invocarem antigas fórmulas e a ensaiarem novas experiências.

O debate sobre a duração da jornada de trabalho, cuja redução fora malfadadamente experimentada em 1982, é retomada pelo governo francês com a eleição do primeiro ministro-socialista Lionel Jospin. Após intensos debates, a lei das " 35 horas", que reduz a duração semanal legal de trabalho de 39 para 35 horas, foi finalmente votada e aprovada.

Na disputa que se trava na arena política em torno do tema da redução da jornada de trabalho, uma das questões mais prementes indaga sobre a efetividade desta política em criar empregos.

Nos limites deste artigo, preocupar-nos-emos, sobretudo, em apresentar as contribuições e insuficiências de um conjunto de análises microeconômicas que, recorrendo ao instrumental das teorias do emprego novo-keynesianas, procuram avaliar os impactos potenciais 
de uma política de redução da jornada de trabalho sobre o volume de emprego da economia.

Para tanto, no segundo tópico deste artigo, apresentaremos em breves linhas os contornos principais da lei das "35 horas" na França, nos momentos de sua proclamação e desdobramentos políticos mais recentes, que acabaram por invalidar de facto o espírito desta medida legal.

A seguir, no terceiro tópico, procuraremos descrever o movimento da duração do trabalho ao longo de um largo período de tempo. Neste caso, pode-se pensar em uma tendência, ao menos para o período mais recente? Em segundo lugar, qual o fator (ou mecanismo) que franqueia o caminho para uma redução da jornada de trabalho?

Num quarto tópico proporemos um modelo propositadamente simplificado do funcionamento de uma política ativa de empregos cujo instrumento privilegiado é a redução da jornada de trabalho. Com base neste modelo, indagaremos como a redução da jornada de trabalho afeta o volume total de trabalho empregado produtivamente. Além disso, procuraremos mostrar que, por variadas razões, há um interesse crescente pelos resultados dos modelos microeconômicos que se propõem a investigar os impactos potenciais de uma política de redução da jornada de trabalho.

Precisamente neste sentido, em um quinto tópico, apresentaremos de forma bastante esquemática os principais resultados de algumas análises econômicas, que, recorrendo ao instrumental econômico oferecido pelas teorias do desemprego de equilíbrio, procuram avaliar as implicações de uma política de redução da jornada de trabalho sobre o volume de emprego da economia, no curto e no longo prazo.

Ocorre que estes modelos recorrem, como procuraremos evidenciar, a uma simplificação muito demasiadamente grosseira da forma pela qual se dará a redução da jornada de trabalho. Sem a pretensão de desenvolver uma abordagem teórica alternativa, essa apreciação nos conduzirá ao sexto tópico deste artigo, que procura evidenciar algumas insuficiências das abordagens da ortodoxia que a nosso ver, obscurecem em muito o alcance potencial da política aqui estudada.

\section{Ascensão e queda da lei das "35 horas" na França}

O projeto de lei que instituiu as "35 horas" de trabalho semanal na França foi votado e aprovado pela Assembléia Nacional francesa em 19 de maio de 1998. 
De acordo com o texto desta primeira lei, a duração da semana legal de trabalho foi fixada em 35 horas a partir de $1^{\mathrm{O}}$ de janeiro de 2000 para as empresas que contavam com mais de 20 empregados, e a partir de $1^{\circ}$ de janeiro de 2002, para as demais empresas. Considerando que as empresas de menor porte enfrentariam maiores dificuldades em se adaptar à nova legislação, um tempo mais dilatado lhes foi concedido.

A lei das "35 horas" foi aplicada a todas as empresas privadas e públicas, aos estabelecimentos públicos de caráter industrial ou comercial, aos escritórios públicos e ministeriais, às profissões liberais, às sociedades civis e sindicais, às associações, aos estabelecimentos hospitalares privados, aos estabelecimentos familiares e cooperativos bem como aos estabelecimentos agrícolas e às empresas de transportes públicos. Somente foram excluídas do campo de aplicação da lei as funções públicas, os estabelecimentos públicos administrativos ou de natureza mista, certas profissões particulares e as atividades marítimas.

Embora o caráter coercitivo da lei da nova duração semanal legal do trabalho só viesse a se manifestar a partir do início do ano 2000, o governo procurou fazer com que as empresas se antecipassem à norma legal. Na realidade, o texto da primeira lei apenas fixava a nova duração legal do trabalho, ou seja o teto a partir do qual as horas de trabalho passam a ser contadas como horas extras. Ao governo, contudo, interessava conduzir o processo de forma que a redução da duração legal ocorresse em paralelo com a redução da sua duração efetiva, condição sine qua non para a criação de novos postos de trabalho.

Conseqüentemente, o governo previu uma ajuda financeira às empresas que procedessem simultaneamente a uma diminuição do tempo de trabalho e a um incremento do número de empregos. Para que pudessem se beneficiar da ajuda financeira do Estado, os acordos deveriam atender determinadas condições.

O fato é que desde 1996, com a Lei Robien, e particularmente após 1998 com a entrada em vigor dos primeiros mecanismos incitativos da Lei das "35 horas", a França viu a aplicação de diversos dispositivos legais de redução da jornada de trabalho produzir resultados.$^{2}$ Em relatório

2 A lei Robien tinha o propósito de dar novo alento ao processo de redução da jornada de trabalho através de incitações financeiras concedidas às empresas que se comprometessem a ampliar, ou ainda a preservar, o volume de emprego. Em 19 de maio de 1998 foi adotada pela Assembléia francesa a primeira lei das "35 horas". De acordo com o texto desta primeira lei de redução da jornada de trabalho, a duração semanal legal do trabalho foi fixada em 35 horas a partir de $1^{\circ}$ de janeiro de 2000 para as empresas que contavam com mais de 20 empregados, e a partir de $1^{\circ}$ de janeiro de 2002 , para as demais empresas. Considerando que as empresas de menor porte enfrentariam maiores dificuldades em se adaptar à nova legislação, um tempo mais dilatado lhes foi concedido. Ademais, várias modalidades de incitações financeiras foram previstas para as empresas que se antecipassem à entrada em vigor da lei e negociassem com seus trabalhadores a redução da jornada de trabalho para o patamar das 35 horas. 
para o biênio 2000-2001, apresentado pelo governo francês ao seu Parlamento, podem ser constatados os principais êxitos desse processo. ${ }^{3}$

Em primeiro lugar, no final do ano de 2001, mais da metade dos assalariados dos setores concorrenciais e associativos já trabalhavam em empresas que haviam passado ao regime das 35 horas. Para o conjunto dos trabalhadores em tempo completo das empresas de 10 assalariados ou mais era possível constatar uma redução média de quase 3 horas da duração semanal do trabalho.

Em segundo lugar, quanto às modalidades de implementação da redução da jornada de trabalho, constatou-se que na metade dos estabelecimentos e para quase $70 \%$ dos trabalhadores (excluindo-se «les cadres», ou seja, os trabalhadores em postos de comando nas empresas) a redução da jornada de trabalho se deu pelo usufruto de dias de repouso suplementares ao longo do ano.

Em terceiro lugar, quanto aos efeitos da redução da jornada de trabalho sobre os salários, constatou-se que muito raramente - e isto para todas as categorias de trabalhadores - a redução da jornada de trabalho se fez acompanhar de uma redução dos salários nominais. Assim, a remuneração de base (excluídas as horas extras) foi, na maior parte dos casos, integralmente compensada pelo aumento do salário horário ou através de uma indenização específica. A partir de 2000, a contrapartida da compensação salarial integral se deu em um terço dos casos na forma de um congelamento dos salários e em quase $15 \%$ dos casos na forma de acordos de moderação salarial.

Em quarto lugar, quanto ao sentimento dos trabalhadores com relação aos impactos da redução da jornada em suas condições de vida pessoal e profissional, quase $60 \%$ dos trabalhadores afetados pela medida declararam ter uma visão positiva do processo contra $13 \%$ que constataram uma degradação de sua situação.

Finalmente, e o mais importante, quanto aos impactos na criação de empregos, estimou-se que desde 1996 até o final de 2001, as medidas de redução da jornada de trabalho e de redução das cotizações fiscais foram responsáveis pela criação de 300 mil empregos, ou seja, $18 \%$ do total de empregos criados neste mesmo período nas empresas privadas não agrícolas. ${ }^{4}$

3 Ver FRANCE. Ministère des affaires sociales, du travail et de la solidarité.

4 São inúmeras as controvérsias a respeito dos reais resultados da aplicação da lei das " 35 horas" na França. Optamos por reproduzir apenas os resultados do balanço oficial do governo, pois uma avaliação criteriosa das diferentes visões dos resultados da aplicação das medidas na França foge ao escopo deste artigo. No entanto, convém destacar, no mesmo sentido das proposições que destacamos, que uma publicação recente afirma ter estimado em 350 mil empregos o impacto direto líquido das medidas de redução da jornada de trabalho entre 1997 e 2002. A esse respeito ver Dares (2003). 
FRACALANZA, P. Limites das abordagens microeconômicas da redução...

Vistos em perspectiva estes resultados impressionam. Contudo, desde 2003, diversas autoridades públicas passaram a ser manifestar pela flexibilização da lei das "35 horas" e, concomitantemente, diversas iniciativas legais produziram modificações substanciais nas regras vigentes, modificações essas que acabaram por comprometer o espírito inicial das medidas de redução da jornada de trabalho. Os mecanismos de flexibilização (assouplissement) atingiram em cheio as principais salvaguardas do mecanismo de redução da jornada de trabalho: a limitação do contingente anual de horas extras e a majoração do pagamento das horas extras.

Com efeito, em janeiro de 2003, a primeira destas iniciativas, a assim denominada Lei Fillon, introduziu diversas medidas de flexibilização da legislação das 35 horas, adentre elas a elevação do teto anual de horas extras (de 130 a 180 horas) e a introdução da possibilidade de uma modulação dos pagamentos das horas extraordinárias segundo o setor de atividade das empresas.

No mesmo sentido, em dezembro de 2004, Jean-Pierre Raffarin anuncia o Contrat France 2005. Além de um novo aumento do contingente anual de horas extras, as novas medidas anunciadas criam um acordo do tempo livre (accord du temps choisi). ${ }^{5}$ Mediante um acordo setorial ou no nível empresarial, o assalariado teria o recurso a horas extras para além do contingente convencional.

Finalmente, com a eleição de Sarkozy, ganharam estímulo e força os argumentos dos partidários do bordão da escolha de travailler plus pour gagner plus ${ }^{6}$ e, assim, pode-se conjeturar que ficam seriamente comprometidas as perspectivas daqueles que se colocam como defensores das medidas de redução da jornada de trabalho.

\section{A redução da jornada de trabalho se configura como uma tendência?}

Podemos sim, dizer que a redução da jornada de trabalho é, efetivamente, uma tendência histórica de longa duração. Quando se reúnem as estatísticas disponíveis sobre a duração anual efetiva do trabalho, constata-se que, para o conjunto dos países industrializados houve nos últimos cento e cinqüenta anos uma importante redução da jornada (Cette \& Taddei 1997: 20-30).

5 Esta medida ganharia reforço com a lei de março de 2005 que incluía entre seus dispositivos outras medidas de flexibilização.

6 O bordão significa trabalhar mais para ganhar mais, ignorando a assimetria constitutiva das das relações de trabalho, como se a escolha do tempo de trabalho fosse prerrogativa dos trabalhadores. 
O gráfico 1 abaixo apresenta a evolução da duração anual efetiva do trabalho por pessoa para alguns países desenvolvidos, entre 1870 e 1987.7 Como é possível verificar neste gráfico, a redução da jornada de trabalho foi de grande magnitude. Na França e nos EUA, particularmente, a duração da jornada de trabalho foi reduzida quase à metade. Se no final do século XIX contavam-se quase 3.000 horas de trabalho, em 1987, nestes países, este patamar era um pouco superior às 1.500 horas de trabalho.

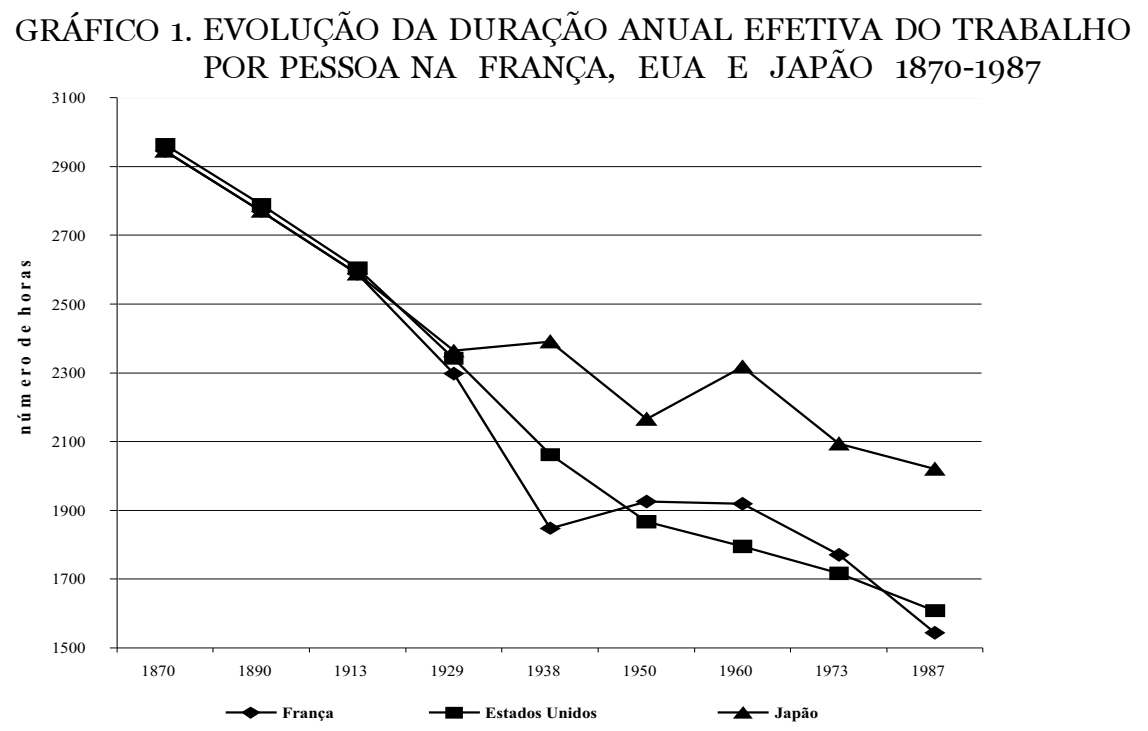

FONTE: Elaborado a partir de tabela apresentada por Maddison, A. (1991). Dynamic forces in Capitalist Development. New York: Oxford University Press, apud Cette \& Taddei (1997:23).

Outro fato importante que podemos concluir da observação desse gráfico é que a redução da jornada de trabalho não seguiu uma trajetória regular. Como é possível verificar, períodos de intensa redução da duração da jornada de trabalho se alternaram com períodos onde esta duração permaneceu estagnada ou mesmo se ampliou em pequena medida.

7 A metodologia do cálculo da duração anual efetiva do trabalho envolve a estimativa da duração média do trabalho daquelas pessoas que estiveram empregadas no período de referência (o ano, para o presente caso), levando-se em conta, ademais, o absenteísmo, as greves, os feriados, dias de descanso e períodos de férias anuais e as horas extras individuais. Para uma exposição das dificuldades metodológicas envolvidas no cálculo e na comparação internacional da duração anual do trabalho ver Cette \& Taddei (1997), especialmente os quadros da página 21 e páginas 32 a 34. 
FRACALANZA, P. Limites das abordagens microeconômicas da redução...

Cabe, portanto, uma pergunta. Esta tendência observada de redução da jornada de trabalho é inexorável?

Seria acertado dizer que não. Em outros períodos da história o movimento foi no sentido contrário a este que relatamos. A bem da verdade, a regulamentação da jornada de trabalho apresenta-se, historicamente, como uma luta multissecular travada pela classe trabalhadora, de um lado, e pela classe capitalista, de outro. Esta história pode ser dividida em dois grandes períodos.

Em um primeiro longo período que se estende do século XIV ao século XVIII, momento de gênese do modo de produção capitalista, há uma extensão progressiva da jornada de trabalho que irá atingir, em fins do século XVIII, limites intoleráveis. ${ }^{8}$ A seguir, em outro período que percorre os séculos XIX e XX assiste-se ao movimento inverso, de lenta redução da jornada de trabalho.

Para aprofundarmos um pouco mais esta importante discussão devemos entender qual é o motor principal que torna possível o movimento de redução da jornada de trabalho.

Sem dúvida, podemos dizer que o avanço tecnológico e o aumento da intensidade do trabalho, ao permitirem um incremento da produtividade dos fatores de produção, franqueiam o caminho da diminuição da jornada de trabalho. Na realidade, porém, a ampliação do excedente econômico, como resultado do incremento da produtividade do capital e do trabalho, pode ter quatro destinações não exclusivas: i) pode ser apropriado privadamente pelos detentores do capital, aumentando a massa de lucros na economia; ii) pode servir para aumentar os salários reais dos trabalhadores; iii) pode ser apropriada pelo Estado que a redistribuirá na forma de bens ou serviços; iv) e, finalmente, pode servir para reduzir a jornada de trabalho.

Concretamente, na realidade histórica vivida em cada país, estas quatro formas de utilização do excedente econômico ampliado combinaramse de formas distintas. No pós Segunda Guerra, por exemplo, em muitos países desenvolvidos, o intenso incremento da produtividade horária do trabalho foi canalizado principalmente para a elevação dos salários dos trabalhadores - o que permitiu a expansão e a sustentação do consumo de massa - como também para a constituição de fundos públicos que financiaram as atividades do Estado de Bem-Estar Social.

\footnotetext{
8 Um vívido e minucioso relato destes limites intoleráveis a que nos referimos pode ser encontrado
} em Marx (1985: vol. I, capítulo VIII). 


\section{Redução da jornada de trabalho: não mais que uma \\ regra de três?}

Numa primeira aproximação, o princípio sobre o qual repousa uma política de redução da jornada de trabalho, apreciada enquanto instrumento para a criação de empregos, parece tão simples que poderíamos indagar legitimamente por que razão afinal tal política tem despertado tantas controvérsias.

É possível pensar que numa dada economia, num dado momento, há uma certa quantidade de trabalho remunerado empregado produtivamente. Esta quantidade de trabalho, abstraindo suas singularidades distintivas, pode ser medida pelo número de horas de trabalho por semana. Para alcançar tal resultado multiplicaríamos, simplesmente, a média da duração semanal efetiva do trabalho pelo número de pessoas que exercem uma atividade remunerada. $\mathrm{O}$ resultado desta operação, expressa em horas de trabalho semanal, representaria o esforço total dispensado nessa economia pelos homens e mulheres que têm um emprego. Poderíamos, então, formular a seguinte proposição: e se esse volume total de trabalho fosse redistribuído ou partilhado entre todos que desejam trabalhar?

Sim, porque hoje é flagrante que com a quantidade de trabalho empregado produtivamente há pessoas que trabalham, enquanto outras não encontram um emprego. Se procedêssemos a uma divisão desse volume total de trabalho entre todos os que desejam trabalhar, o desemprego deveria desaparecer. O que significaria dizer que para que todos pudessem trabalhar, todos deveriam trabalhar menos. ${ }^{9}$

Esse raciocínio, aparentemente bastante lógico, é ditado pelo senso comum e como em muitos outros domínios os economistas se precipitam em demonstrar que nessas questões muitos obstáculos podem surgir entre a taça e os lábios.

Um primeiro obstáculo se ergue porque em nosso modelo simplificado supusemos, implicitamente, que o volume total de trabalho permanece inalterado quando ocorre a redução da jornada de trabalho. O problema, contudo, é justamente este. Podemos legitimamente acreditar que a redução da jornada de trabalho não irá afetar o volume total de trabalho empregado na economia? Ou, em outros termos, temos razões para crer que a demanda de trabalho por parte das empresas não irá se alterar por ocasião de uma política de redução da jornada de trabalho?

9 A propósito, esse é o mote do célebre livro de Aznar (1993) intitulado Travailler moins pour travailler tous. 
FRACALANZA, P. Limites das abordagens microeconômicas da redução...

Esta é, seguramente, a questão que mais desperta o interesse dos especialistas e do público em geral. Uma política de redução da jornada de trabalho implica, é bem verdade, custos não desprezíveis. Porém, nem todos são igualmente palpáveis e a importância de muitos depende das hipóteses iniciais formuladas.

Dessa forma, quais os custos das alterações das rotinas de trabalho para os trabalhadores? Quais os custos para os empresários dos eventuais e, talvez, onerosos processos de reorganização do trabalho? Quais os reflexos da redução da jornada de trabalho sobre os salários? - questão que interessa vivamente aos trabalhadores, empresários e governo. Quais os reflexos da redução da jornada de trabalho na competitividade das empresas e do país? Qual o montante dos subsídios que deverão ser concedidos pelo Estado?

Mesmo com tantas dúvidas, se a política de redução da jornada de trabalho lograr reduzir o desemprego um importante benefício terá sido atingido. Portanto, a primeira questão colocada aos economistas é justamente esta : a redução da jornada de trabalho pode criar empregos? Em segundo lugar, numa ponderação de seus custos e benefícios, esta é a política mais eficiente?

As respostas a estas questões foram e são conduzidas em dois níveis analíticos.

Há, por um lado, os estudos de recorte macroeconômico que se dedicam a avaliar as implicações de uma política de redução da jornada de trabalho sobre o volume de emprego da economia tendo como base poderosos modelos econométricos que procuram descrever o comportamento da economia como um todo. Essas simulações, é bem verdade, constituem importantes referências. Porém, como na concepção de tais modelos a duração da jornada de trabalho é variável ausente, os resultados previstos em termos da criação de empregos dependem fortemente da seleção das hipóteses iniciais. ${ }^{10}$

Por outro lado, outros estudos dedicam-se a avaliar os impactos microeconômicos de uma política de redução da jornada de trabalho, isto é, como uma alteração das normas legais que disciplinam a duração do trabalho afeta os cálculos e ações dos agentes econômicos, trabalhadores e empresários. Nos limites deste artigo, concentrar-nosemos na descrição e análise dos resultados destas análises microeconômicas.

10 Em artigo publicado na revista Liaisons Sociales (1998:1), que traz um balanço dos resultados de algumas estimativas destes modelos para o caso francês, afirma-se : " $O$ conhecimento das hipóteses é essencial para a avaliação dos resultados obtidos. Em particular, os resultados quantitativos obtidos - principalmente o número de empregos criados - dependem grandemente das hipóteses consideradas" (tradução nossa). 
O argumento que sustenta a importância da diminuição de horas trabalhadas pode ser sumariado como segue. Há um entendimento largamente consensual, em parte reforçado pelos resultados da experiência de 1982 na França, de que a redução da jornada de trabalho não deve ser negociada de forma centralizada. Portanto, se as negociações devem ocorrer nos setores produtivos, ou até mesmo nas empresas, apenas uma análise microeconômica seria capaz de corretamente interpretar e prever a correção dos rumos das ações dos agentes quando ocorre uma alteração da legislação trabalhista. Mas afinal, que tipos de mudanças são previstas?

Em primeiro lugar, a redução da jornada exige uma reorganização dos processos de trabalho. Essa reorganização pode envolver, entre outros aspectos, uma profunda mudança nos horários de trabalho, sobretudo se os acordos entre empresários e trabalhadores previrem o recurso a uma das formas de modulação desses horários. Por outro lado, se as empresas considerarem vantajosa uma ampliação da duração de utilização dos equipamentos, novas equipes de trabalho deverão ser contratadas e conseqüentemente novos turnos de trabalho serão criados. É certo que neste campo dificilmente o governo poderia estabelecer uma regra única à qual todas as empresas deveriam aderir forçosamente.

Em segundo lugar, o processo de redução da jornada de trabalho envolve obrigatoriamente uma renegociação dos salários. Com efeito, ao implementar uma política de redução das horas trabalhadas, o que fazer dos salários? Para responder a essa questão, pode-se analisar as repercussões da compensação salarial em três diferentes cenários.

No primeiro cenário, depois da redução da duração da semana legal de trabalho, o salário horário não sofre qualquer modificação. A rigor, isso representa uma diminuição dos salários semanais percebidos pelos empregados da mesma magnitude da redução da jornada de trabalho e neste caso diríamos que não houve compensação salarial.

No segundo cenário, o salário semanal não é alterado depois da implementação da redução da jornada de trabalho. Neste caso ocorre um aumento do salário horário e diríamos que foi adotada uma compensação salarial integral.

No terceiro cenário, o nível do salário semanal se situa entre os limites estabelecidos no primeiro e segundo cenários. Neste caso diríamos que há uma compensação salarial parcial quando da redução da jornada de trabalho.

Portanto, a reorganização dos processos de trabalho e as negociações salariais são duas entre muitas outras questões que serão decididas nos 
FRACALANZA, P. Limites das abordagens microeconômicas da redução...

setores produtivos ou nas empresas. A consideração de que uma mudança das normas legais com respeito à duração da jornada de trabalho deveria ser flexível o bastante para que as diferentes empresas encontrassem caminhos próprios no processo de adaptação às novas regras aumenta o interesse pelos resultados e possibilidades sugeridos pelos estudos microeconômicos.

Muitos são os economistas que a partir de modelos microeconômicos têm se debruçado sobre a questão da redução da jornada de trabalho. Consideramos particularmente interessante a linha teórica que recorre ao instrumental das teorias de emprego novo-keynesianas. Entre estes trabalhos, destacamos o de Corneo (1994) e o de D'Autume \& Cahuc (1997) que procuram decifrar as múltiplas dimensões da relação entre a jornada de trabalho e o nível de emprego no curto e no longo prazo.

\section{Análises microeconômicas da redução da jornada de trabalho}

O artigo de Corneo (1994) realiza uma competente revisão e uma síntese da literatura econômica que recorre aos modelos microeconômicos na tentativa de avaliar os impactos de uma política de redução da jornada de trabalho sobre o volume de emprego. Já o artigo de D'Autume \& Cahuc (1997) é também bastante representativo do pensamento da ortodoxia sobre a redução da jornada de trabalho. Neste artigo há a inegável vantagem de que os autores procuram incorporar em suas reflexões os efeitos de algumas variáveis normalmente descartadas nas tradicionais análises microeconômicas da redução da jornada de trabalho, entre as quais a duração de utilização dos equipamentos e o grau de compensação salarial.

Estes autores exploram as implicações dos desenvolvimentos teóricos mais recentes da tradição que se convencionou denominar de teorias novo-keynesianas do mercado de trabalho, ou seja, o conjunto de abordagens microeconômicas que procuram explicar a natureza do desemprego involuntário a partir da compreensão dos microfundamentos que sustentam a rigidez dos salários reais num nível acima daquele de pleno-emprego, num mundo marcado por imperfeições concorrenciais e informacionais presentes também no mercado de trabalho. ${ }^{11}$

11 Uma boa referência destas abordagens teóricas também denominadas de teorias do desemprego de equilíbrio por alguns autores, ou ainda de novas teorias do mercado de trabalho pode ser encontrada em Perrtot (1995). Para uma leitura em português ver Fracalanza (2002). 
Não cabe aqui reproduzir a mecânica de funcionamento dos modelos microeconômicos explorados por estes autores ${ }^{12}$ Procuraremos, tão somente, apresentar as principais conclusões a que são conduzidos estes autores.

Em síntese, segundo a apreciação de D'Autume \& Cahuc (1997) e Corneo (1994), a relação entre a duração do trabalho e o emprego é bastante difícil de ser apreendida. Com efeito, algumas condições muito restritivas devem ser satisfeitas para que uma política de redução da jornada de trabalho possa ser bem sucedida:

1. A exigência dos assalariados em termos de compensação salarial deve ser moderada;

2. A produtividade horária do trabalho deve se ampliar de maneira significativa;

3. A duração da utilização dos equipamentos produtivos não deve se ver diminuída.

A primeira condição, sobre a compensação salarial e seus reflexos sobre os custos salariais é certamente a questão mais delicada.

Essa discussão desperta duas diferentes questões. Por um lado, há a questão salarial propriamente dita - o embate entre as vontades incongruentes dos trabalhadores e empresários no confronto pela determinação do nível de salário nominal. O poder de barganha dos sindicatos e dos empresários, o conteúdo e as modalidades de implementação da política de redução da jornada de trabalho são temas que têm lugar destacado nesse debate.

Por outro lado, para muitos autores a questão do nível salarial está no cerne da determinação do volume de emprego. Por essa razão, a maior parte dos esforços e das reflexões sobre o tema da redução da jornada de trabalho será dedicada a avaliar e interpretar como evoluirão as relações que se supõem existir entre salários e empregos.

$\mathrm{Na}$ avaliação dos autores que destacamos, mesmo num cenário mais favorável ao emprego, uma compensação salarial integral permanece excluída, pois ao final ela produzirá uma diminuição dos lucros. Embora no curto prazo uma diminuição dos lucros apenas desencadeie uma reação negativa da parte dos empregadores, a longo prazo os investimentos se veriam reduzidos e, em conseqüência, o nível de emprego cairia.

12 Uma apresentação sistemática da mecânica de funcionamento destes modelos pode ser encontrada em Fracalanza 2001: especialmente capítulo 3. 
A segunda condição, sobre os ganhos de produtividade horária do trabalho, permite, até um certo ponto, contrabalançar o aumento de custos devido à compensação salarial e à diminuição da duração da utilização dos equipamentos. Dessa maneira, os ganhos de produtividade aparecem como uma das fontes de financiamento da redução da jornada de trabalho.

Finalmente, a terceira condição, que diz respeito à reorganização da duração de utilização dos equipamentos, torna-se exeqüível em virtude do processo de reorganização do trabalho, acompanhado geralmente da implementação da redução da jornada. A manutenção, e até o alongamento da duração da utilização dos equipamentos, representa outra fonte potencial de financiamento para fazer face aos custos da diminuição dos horários de trabalho.

O problema é que a realização de cada uma dessas três condições depende de múltiplas variáveis cujas relações não são bem compreendidas pela ciência econômica. Para preencher essas lacunas, a escolha conscienciosa das hipóteses iniciais se mostra muito importante e resultados divergentes são obtidos em razão dessas escolhas.

Face ao reconhecimento das dificuldades da ciência econômica em compreender as implicações de uma política de redução da jornada de trabalho, qual é a recomendação dos autores da ortodoxia?

Prudência. Corneo (1994) afirma que uma política de redução da jornada de trabalho, cujos efeitos não podem ser bem avaliados pela ciência econômica apenas merece o título de aventureira. D'Autume \& Cahuc (1997) tomam uma outra via, procurando compreender quais são os meios de favorecer a eficiência de uma redução da jornada de trabalho em termos de geração de empregos. Partindo da apreciação que a redução da jornada de trabalho não é uma solução miraculosa para o problema do emprego, eles advogam a urgência da adaptação das instituições do mercado de trabalho a fim de aumentar o impacto potencial dessa política.

Em primeiro lugar, seria necessário instituir um mecanismo que garantisse a representação dos interesses dos desempregados e dos trabalhadores que têm empregos precários nas negociações. Em segundo lugar, seria preciso adaptar o modo de formação dos ganhos dos trabalhadores privados de serviço. A solução imaginada consiste em indexar o salário desemprego à remuneração média percebida pelos trabalhadores que possuem um emprego. Finalmente, deveriam ser criados mecanismos para conscientizar a sociedade da importância do tempo livre e das atividades não mercantis. 


\section{Discussão final}

A que ponto nos conduzem estas análises microeconômicas dos impactos de uma política de redução da jornada de trabalho para a criação de empregos?

Em primeiro lugar, a nosso ver, estas análises têm o mérito de evidenciar que a eficácia da proposta de redução da jornada de trabalho em termos da criação de empregos depende da evolução de um conjunto de condições por vezes bastante restritivas. Contudo, cremos que a forma pela qual se integra a redução da jornada de trabalho nestes modelos é por demais simplificada. O risco desta simplificação é tornar muito mais distantes as condições de realização da proposta de redução da jornada no sentido de um aumento no volume de emprego.

Na realidade, se nos movêssemos nos mesmos estreitos limites do terreno considerado por estes autores seríamos forçados a admitir que a redução da jornada de trabalho não é uma política eficiente - quiçá tampouco eficaz - para minorar os males do desemprego.

Sua primeira insuficiência decorre da própria conceituação do desemprego nos termos da teoria microeconômica neoclássica. Para estes teóricos, o desemprego - resultado das formas contratuais acordadas entre indivíduos «hipercalculadores» - é a manifestação de uma subutilização crônica de um fator produtivo no processo de criação de riquezas. Seja como for, os arranjos alcançados são «eficientes» economicamente e, portanto, a solução para o problema do desemprego é envidar esforços para encontrar os meios que possibilitem aumentar a taxa de utilização do capital humano sem afrontar as condições de rentabilidade dos empreendimentos produtivos.

Sem desqualificar integralmente a contribuição destas abordagens - a descrição rigorosa da interação entre algumas variáveis pode ser fonte de inspiração - a compreensão da economia no sentido estreito da «eficiência econômica» pode lançar poucas luzes na resolução de um problema cujas dimensões ela mal abarca.

O que se está a dizer é que o desemprego não é um problema de «eficiência econômica», mas sim uma questão que coloca em xeque a própria sobrevivência do homem. Esse problema exige de nós um esforço para nos afastarmos dos marcos destas mecânicas elegantes e pensarmos na economia, como propõe Polanyi (1983), no seu sentido substantivo, ou seja, que nenhum ser humano pode se manter vivo e em condições dignas sem um ambiente material que o sustente. E em nossa sociedade, o 
FRACALANZA, P. Limites das abordagens microeconômicas da redução...

trabalho continua a representar a condição privilegiada de inserção social. ${ }^{13}$

Sua segunda insuficiência decorre do que acabamos de expor. Em virtude de sua incompreensão do significado do desemprego, a teoria microeconômica do mercado de trabalho não está aparelhada para mensurar, de forma equilibrada, os custos sociais provocados por este mal. No campo da teoria neoclássica, a principal conseqüência do desemprego, para os indivíduos afetados, é a cessação da renda, cujos efeitos danosos são parcialmente compensados pelas «oportunidades exteriores», ou seja, pelos auxílios aos desempregados vertidos pelo Estado. Portanto, a contabilidade dos custos do desemprego para a sociedade envolve, o mais das vezes, apenas os montantes das transferências sociais destinadas aos trabalhadores privados de emprego.

Fazendo nossas as palavras de Sen (1997), uma avaliação criteriosa dos custos sociais do desemprego deve incluir, entre outros fatores: a consideração da produção potencial não exercida; os custos decorrentes da exclusão social, da desorganização da vida familiar e da ruptura das relações sociais que acometem os desempregados; a perda das qualificações laborais, sobretudo para os desempregados de longa duração; as repercussões psicológicas e os estados patológicos originados da experiência dolorosa do desemprego; e, finalmente, a degradação dos valores sociais e do sentimento de responsabilidade nas sociedades que sofrem cronicamente deste mal (Sen 1997).

A terceira insuficiência destas abordagens microeconômicas neoclássicas do mercado de trabalho decorre da circunscrição de seu campo de análise. Os teóricos desta tradição acreditam que o problema e as soluções para o desemprego podem ser encontrados no mercado de trabalho e, no máximo, na interdependência deste mercado com o mercado de bens.

Contudo, dentro da lógica de mercado, o desemprego tem poucas chances de ser resolvido. A depender dos mecanismos de mercado, dissera Keynes (1985), a economia pode permanecer indefinidamente numa situação de equilíbrio sem pleno emprego.

O que falta, portanto, aos teóricos neoclássicos? Falta justamente a compreensão de que os mecanismos de mercado não podem conduzir es-

13 No momento atual, é importante considerar, o processo de urbanização e a conseqüente desestruturação das tutelas tradicionais e das formas orgânicas de solidariedade tornam vitais os elementos de proteção construídos pelo Estado. "Les éradiquer ne serait pas seulement supprimer des "acquis sociaux" plus ou moins contestables, mais casser la forme moderne de la cohésion sociale." A esse respeito ver Castel (1995: 435-460). 
pontaneamente a economia para uma situação de pleno emprego - e não podem fundamentalmente porque o movimento do capital tende a repelir e não a absorver o trabalho vivo - e, logo, outra lógica, não mercantil, deve ser mobilizada para que o importante objetivo da garantia de emprego seja atingido. Em nossa sociedade, esta lógica - da autoridade - é exercitada pelo Estado, seja no estímulo de um nível de demanda efetiva capaz de absorver toda a parcela da população ativa desejosa de trabalhar, seja na orquestração de um conjunto de normas jurídicas e de um esquema de transferências sociais que garantam um patamar mínimo de proteção social.

Todavia, no arcabouço das doutrinas liberais, o Estado não tem um papel relevante a desempenhar, nem mesmo nas modernas roupagens das teorias do desemprego de equilíbrio. Ainda mais num momento em que se clama, no mundo inteiro, que os Estados zelem pela convergência de suas políticas no atendimento das metas de estabilização monetária e austeridade fiscal.

Sua quarta insuficiência decorre das cláusulas coeteris paribus. É certo que toda análise econômica deve se valer do artifício de fixar algumas variáveis para estimar os efeitos produzidos pelas mudanças das variáveis selecionadas. Porém, cremos que neste caso as variáveis exógenas dos modelos neoclássicos são justamente aquelas de cuja evolução depende o dinamismo do movimento de redução da jornada de trabalho.

A primeira destas variáveis é a taxa de crescimento da produtividade do trabalho que, como já foi destacado, é condição necessária para a realização da redução da jornada. ${ }^{14}$

Assim, numa perspectiva dinâmica, a consideração da evolução do progresso técnico permitiria conceber acordos salariais que previssem uma compensação salarial integral, no momento da passagem para os horários de trabalho reduzidos, e a adoção de cláusulas de moderação salarial para alguns anos seguintes, o que permitiria amortecer, num prazo mais dilatado, os impactos iniciais sobre os custos salariais. ${ }^{15}$

A segunda variável ausente é o crescimento econômico. Todavia, as condições de realização de uma política de redução da jornada de trabalho não têm como ser consideradas em abstrato, independente-

14 Com efeito, a teoria neoclássica não tem como incorporar em seus modelos o crescimento da produtividade do trabalho já que no horizonte de tempo de suas análises as opções tecnológicas são consideradas, para efeitos práticos, como dadas e imutáveis.

$15 \mathrm{O}$ que, ademais, está a ocorrer na realidade como bem demonstra o relatório preparado por Acouturier \& Coutrot (2000) e principalmente o relatório do governo francês ao seu parlamento, (FRANCE. Ministère des affaires sociales, du travail et de la solidarité 2002), que sistematiza os principais resultados colhidos pela aplicação da lei das “35 horas" na França. 
FRACALANZA, P. Limites das abordagens microeconômicas da redução...

mente de uma prospecção sobre a evolução dos agregados macroeconômicos. A experiência de 1982 já mostrara que os impactos potenciais benéficos da redução da jornada de trabalho são severamente atenuados numa conjuntura recessiva.

Já num momento que sinaliza o crescimento econômico a redução da jornada de trabalho tem muito mais chances de êxito. Com a expansão da atividade econômica os impactos iniciais negativos sobre a rentabilidade das empresas são melhor suportados. Também, com o crescimento do ritmo de atividade e com a conseqüente diminuição das taxas de desemprego, os sindicatos se encontram mais fortalecidos e podem conquistar condições mais favoráveis aos trabalhadores. Além disso, a redução da jornada de trabalho produz o resultado de elevar a elasticidade do emprego com relação ao crescimento - o que cria as condições para um crescimento «mais rico em empregos». Finalmente, como último elo de um círculo virtuoso, a redução do desemprego em ritmo mais acelerado contribui para a melhoria do estado das expectativas.

Em síntese, a apresentação destas insuficiências dos modelos sobre o mercado de trabalho na tradição neoclássica pode ser lida também como uma linha de argumentação que procura demonstrar que as condições de sucesso de uma política de redução da jornada de trabalho e, em particular, da lei das "35 horas" na França, são mais amplas e generosas do que querem nos fazer crer os autores da ortodoxia.

\section{Referências}

ACOUTURIER, A. \& COUTROT, T. (2000). Prophètes en leur pays: les pionniers de 35 heures et les autres. Paris: rapport du CSA pour la DARES, janvier.

AZNAR, G. (1993). Travailler moins pour travailler tous. Paris: Syros.

CASTEL, R. (1996). Les métamorphoses de la question sociale: une chronique du salariat. France: Editions Fayard.

CETTE, G. \& TADDEI, D. (1997). Réduire le temps de travail: de la théorie à la pratique. Paris: Le Livre de Poche.

CORNEO, G. (1994). "La réduction du temps de travail dans les modèles de chômage d'équilibre: une revue de la litteérature." Economie et Prévision, 4 (115): 63-73.

DARES, (2003). Les politiques de l'emploi et du marché du travail. Paris : La Découverte.

D‘AUTUME, A. \& CAHUC, P. (1997). "Réduction de la durée du travail et emploi: une synthèse.” In CAHUC, P. \& GRANIER, P. (Coord.). La réduction du temps de travail: une solution pour l'emploi? Paris: Editions Economica. 
FRACALANZA, P. S. (2001). Redução do tempo de trabalho: uma solução para o problema do desemprego? Campinas: tese de doutorado, Universidade Estadual de Campinas, Programa de Pós-Graduação em Teoria Econômica.

FRACALANZA, P. S. (2002). "Uma leitura das teorias do desemprego de equilíbrio." Revista EconomiA 3 (1): 77-111.

KEYNES, J. M. (1985) [1936]. A Teoria Geral do Emprego do Juro e da Moeda. São Paulo: Nova Cultural.

FRANCE. Ministère des affaires sociales, du travail et de la solidarité (2002). La réduction négociée du temps de travail: bilan 2000-2001. URL [On-line]: http: / / www.ladocumentationfrancaise.fr/rapports-publics / 024000506/index.shtml. Acesso em 23 de agosto de 2007.

LIAISONS SOCIALES (1998). "Trois études économiques sur les 35 heures.” Liaisons sociales, Cahier joint au número 12619 (22).

MARX, K. (1985). O Capital. São Paulo: Nova Cultural.

PERROT, A. (1995). Les nouvelles théories du marché du travail. Paris: Editions La Découverte.

POLANYI, K. (1983). La sussistenza dell'uomo: il ruolo dell'economia nelle società antiche. Torino: Giulio Einaudi Editore.

SEN, A. K. (1997). "L'inégalité, le chômage et l'Europe d'aujourd'hui." Revue Internationale du Travail 136 (2): 169-186.

SUMMERS, L. H. \& BLANCHARD, O. J. (1990). "Hystheresis and the european unemployment problem.” In SUMMERS, L. H. Understanding unemployment. Cambridge: The MIT Press.

Submissão: 3 de abril 2007 Primeira resposta: 01 de julho de 2007 Aceite: 01 de agosto de 2007 